\title{
PRIMEIRA ELEIÇÃO PARA DIRETORES ESCOLARES NO MUNICÍPIO DE DUQUE DE CAXIAS/RJ: A PERCEPÇÃO DE ALGUNS SUJEITOS
}

\section{FIRST PRINCIPAL ELECTIONS IN DUQUE DE CAXIAS/RJ: SUBJECTIVE PERCEPTION UNDER FREIRIAN PERSPECTIVE}

\author{
ANDRADE, Ana Paula Menezes ${ }^{1}$ \\ PORTO, Jane Ferreira ${ }^{2}$ \\ RIBEIRO, Márcia Campos ${ }^{3}$
}

\section{RESUMO}

Este texto tem como objetivo trazer reflexões relativas às experiências vividas pelos diferentes sujeitos que compõem as comunidades escolares de Duque de Caxias durante a Primeira Eleição Para Diretores desta rede de ensino. Foram compilados relatos utilizando como principal meio de comunicação as redes sociais. Algumas questões, como a desinformação da comunidade escolar, a ausência de divulgação dos acontecimentos e a ausência de discussão antecipada e aberta acerca da elaboração da metodologia a ser adotada durante o processo, bem como a notada reprodução das atitudes tomadas por cidadãos durante processos eleitorais em outras esferas pareceram bem evidentes após a leitura dos relatos remetendo a uma necessária discussão.

PalavRAS-ChaVe: Gestão Escolar; Eleição de Diretores; Exercício da democracia.

\begin{abstract}
This text aims to reflect on the experiences of the different subjects in the school communities of Duque de Caxias during their first election for school principals. Reports were compiled using social networks as primary means of communication. Some questions, such as the misinformation of the school community, the absence of a disclosure of the events and the absence of early discussion about the preparation of the methodology to be adopted during the process, as well as the reproduction of actions taken by citizens during electoral processes in other spheres, were evident from reading the reports referring to a necessary discussion.
\end{abstract}

KEY WORDS: School Management; Election of Directors; Exercise of democracy.

\footnotetext{
${ }^{1}$ Mestranda do Programa de Pós-Graduação de Ensino em Educação Básica do Instituto de Aplicação Fernando Rodrigues da Silveira (CAp-UERJ); Professora da Secretaria Municipal de Educação de Duque de Caxias.

${ }^{2}$ Universidade Estadual de Campinas.

${ }^{3}$ Instituto para Capacitação Profissional - Ceará.
} 


\section{INTRODUÇÃO}

Segundo o atlas do município organizado pelo Professor André Tenreiro Silva (2012), Duque de Caxias, durante os primeiros anos da República, fazia parte do Município de Nova Iguaçu, uma localidade de constantes alagamentos e surtos de febre amarela, conhecida como "terra sem lei". A proximidade com o Rio de Janeiro, a presença da estação de trem e o crescimento de loteamentos urbanos atraíram muitos imigrantes, que chegavam à procura de emprego e de um lugar mais barato para viver. Nos anos trinta, foram realizadas obras como aterros, drenagem de rios e instalação de bicas d'água tratada.

Apesar das melhorias, a administração em Nova Iguaçu era distante e os serviços prestados ao distrito eram precários. Dessa forma, lideranças mobilizaramse para valorizar a região. Em 1930, a troca de placas da estação ferroviária "Merity", retirando a placa e colocando, no lugar, uma nova, com a inscrição "Caxias" fez emergir, após movimentos políticos, o município de Duque de Caxias, criado a partir do Decreto Lei 1055, de 31/12/1943, hoje formado pelos distritos de Duque de Caxias, Campos Elíseos, Imbariê e Xerém, respectivamente 4 .

A primeira grande indústria da cidade foi a Fábrica Nacional de Motores (FNM), projetada para produzir motores de aviões para as tropas aliadas na Segunda Guerra. Atualmente a economia do município baseia-se principalmente nas atividades industriais, de comércio e serviços, tendo como destaque a refinaria de petróleo de Duque de Caxias (REDUC), localizada em Campos Elíseos que, de acordo com Braz \& Almeida (2010), chegou ao município em 1961 (BRAZ; ALMEIDA, 2010).

Apesar da riqueza econômica produzida no município, o Índice de Desenvolvimento Humano (IDH) ainda é baixo, em comparação com outros municípios do Estado (0,711 contra 0,837 no município de Niterói, conforme dados do IBGE no Censo de 2010), revelando condição de carência vivida pela maioria da população.

Conhecida como uma rede de ensino que enfrenta as dificuldades geradas pela indicação dos Diretores das Unidades Escolares, a Rede Municipal de Duque de Caxias passou no último ano pelo seu primeiro processo de escolha democrática dos dirigentes de suas escolas.

Após muitas pesquisas e reflexões sobre escola e democracia, professores e funcionários representados por seu sindicato chegaram há alguns anos à conclusão da extrema contradição entre querer tornar o espaço da escola democrático, quando

\footnotetext{
${ }^{4} \mathrm{O}$ primeiro distrito, onde se localiza o Centro do município, limita-se geograficamente com a Cidade do Rio de Janeiro e é onde estão concentradas a maioria das atividades de comércio e serviços, uma área urbana. $\mathrm{O}$ segundo distrito, que faz limite com todos os outros distritos, embora seja uma área mais urbana que rural, ainda carece de infraestrutura. Já o terceiro, limitando-se ao segundo e quarto distritos, apresenta características mistas com áreas urbanas e rurais se assemelhando muito ao quarto distrito, também com relação ao clima mais fresco pela localização próxima à Serra de Petrópolis.
} 
DOI: $10.12957 /$ e-mosaicos.2017.30483

ainda se encontravam nas escolas Diretores indicados por entidades políticopartidárias, desencadeando-se processos de luta por direções eleitas para atuarem nas escolas municipais.

De maneira geral, a rede de ensino de Duque de Caxias atende a alunos da classe popular, o que pode influenciar o modo como a comunidade vê a escola e participa em suas decisões, e conta com aproximadamente 178 escolas, 5.700 professores, 1.400 funcionários e cerca de 80 mil alunos, distribuídos nos quatro Distritos do município.

A Secretaria Municipal de Educação (SME) atende as Unidades Escolares, de modo a garantir um calendário que, em constante luta com a categoria e seu sindicato, contemple espaços formativos de estudos, planejamento e de encontro com as famílias.

\section{Gestão Democrática}

O Artigo 206 da Constituição Federal de 1988 elenca, como princípio, a gestão democrática do ensino. Porém, parece que ainda não existe o reconhecimento da demanda pela democratização da gestão escolar de maneira geral. Tal qual a experiência em Duque de Caxias.

A Lei de Diretrizes e Bases da Educação Nacional (LDB 9394/96) prevê, em seu Art. $3^{\circ}$ inciso VIII, o princípio da gestão democrática para as redes públicas de ensino, devendo Estados e municípios realizar a regulação das práticas de gestão democrática em suas redes. Ainda o Art. $2^{\circ}$ inciso XI do Plano Municipal de Educação de Duque de Caxias, publicado em 2015, prevê o fortalecimento da democracia na gestão das escolas da rede municipal.

Tradicionalmente, as escolas da rede de Duque de Caxias estavam sujeitas à indicação dos gestores por parte de entidades político-partidárias. Essa indicação, embora tenha logrado êxito na qualidade do trabalho em algumas unidades escolares, não fortalece a prática da democracia nem a consolidação de práticas pedagógicas. Assim, a experiência da escolha do gestor pelas comunidades escolares dessa rede de ensino é um campo pelo qual ainda se transita pelo tato, na tentativa de crescimento dos sujeitos.

Cabe, então, analisar a adequação das ações relativas ao processo eleitoral, quando e como as ações, na opinião dos envolvidos, deveriam ocorrer visando maior legitimidade.

Duas questões foram colocadas aos mais diferentes sujeitos participantes da comunidade escolar, ouvindo profissionais dos quatro Distritos, através das redes sociais: "Qual a sua opinião a respeito do processo de eleição de diretores escolares ocorrido no ano passado?" e "Como você vê a questão do relacionamento professoraluno, escola-comunidade, durante o processo de eleição para Diretores?", para as 
e-Mosaicos - Revista Multidisciplinar de Ensino, Pesquisa, Extensão e Cultura do Instituto de Aplicação Fernando Rodrigues da Silveira (CAp-UERJ)

V. 6 - N. 13 - DEZEMBRO 2017 - ISSN: 2316-9303

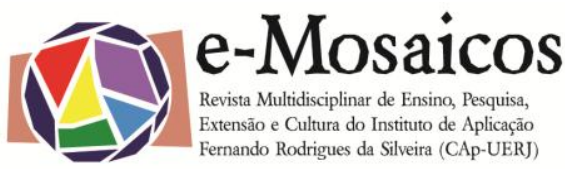

DOI: $10.12957 /$ e-mosaicos.2017.30483

quais se obtiveram as respostas contidas no corpo deste artigo, sendo garantido o anonimato como modo de preservar a identidade dos sujeitos pesquisados.

\section{Eleição para Diretores Escolares de Duque de Caxias: O QUE DIZEM OS SUJEITOS DESSE PROCESSO}

Após anos de luta por uma escolha mais apropriada dos diretores de suas unidades escolares, professores, funcionários, alunos e responsáveis passaram pela primeira vez por esse processo de escolha. Após muita expectativa, em onze de maio de 2015, a Prefeitura, o Poder Executivo, por meio do prefeito em exercício à época, Senhor Alexandre Cardoso, publicou o Decreto 6542/15, que dispunha sobre a eleição de Diretores e Vice-Diretores das Unidades Escolares (U.E.) de Duque de Caxias. Neste documento foram determinadas as normas gerais para a realização do processo de eleição de gestores das Unidades Escolares. Dentre as determinações estavam os requisitos para registro de candidatura ao cargo de Diretor e/ou ViceDiretor nas U.E., a saber: ser servidor público municipal da Secretaria de Educação, detentor de cargo efetivo, estar em exercício pleno de suas funções na Rede Municipal de Educação por no mínimo 03 (três) anos, formalizar a sua chapa de candidatura em termo próprio e no respectivo prazo e possuir disponibilidade para trabalhar 40 (quarenta) horas semanais.

Visando regulamentar outros aspectos do pleito eleitoral, também foram publicadas as Portarias no 34/2015, no 61/2015, no 80/2015 e no 64/2015; o documento Orientações Gerais - $1^{\text {a }}$ Eleição para Diretores, Vice- Diretores e Conselhos Escolares; o Regimento da Primeira Eleição Para Diretores e Vice-Diretores das Unidades Escolares da Rede Pública Municipal de Duque de Caxias; além de cartazes e cartas à comunidade.

Para contribuir com uma reflexão sobre os acontecimentos durante a eleição, iniciou-se uma coleta de dados através da seguinte pergunta: Qual a sua opinião a respeito do processo de eleição de diretores escolares ocorrido no ano passado?, que foi encaminhada para colegas de diferentes unidades escolares dentro da rede municipal, bem como para alguns colegas que ora compunham o quadro de funcionários da Secretaria Municipal de Educação.

Uma escola democrática, para Paulo Freire (1996), seria aquela em que as ações se construiriam com base nos diálogos e acordos gerados pelo grupo, a educação emancipadora que tanto se almeja precisa passar antes pela tolerância e respeito ao outro.

É no respeito às diferenças entre mim e eles ou elas, na coerência entre o que faço e o que digo, que me encontro com eles ou com elas...Viver a abertura respeitosa aos outros e, de quando em vez, de acordo com o momento, tomar a própria prática de abertura ao outro como objeto da reflexão crítica deveria fazer parte da aventura docente. A razão ética da abertura, seu fundamento político, sua 


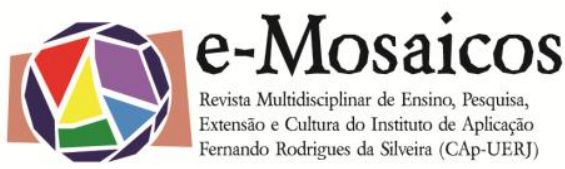

DOI: $10.12957 /$ e-mosaicos.2017.30483

referência pedagógica; a boniteza que há nela como viabilidade do diálogo (FREIRE, 1996, p. 50-51).

A própria ideia de um processo eleitoral já parece provocar nas pessoas um certo grau de euforia, questionamentos e posicionamentos diferenciados pelos interesses que se apresentam pelas diferentes propostas. Nas escolas, porém, se tem como princípio que a ética, o respeito e a urbanidade, são valores que devem ser tratados pedagogicamente e aplicados na rotina diária. Mas, na contramão desta premissa, o que aconteceu dentro das unidades escolares não foi em nada diferente do que o que ocorre nas eleições municipais, por exemplo. Daí o questionamento: 0 que os alunos aprenderam com o processo eleitoral?

Perrenoud (2000) esclarece que antes da segunda guerra mundial, não se tinha o fracasso escolar como um problema e que somente após os anos cinquenta é que se começa a pensar no assunto, justamente pelo fato de que antes a educação era controlada, por assim dizer, para a manutenção da ordem social, havia quem nascesse para governar, e esse precisava estudar para tornar-se uma pessoa "culta" e capaz de conduzir aqueles que, nascidos para o trabalho, bastava que soubessem ler, escrever e calcular... (PERRENOUD, 2000, p. 28).

Pareceu, desta forma, que, durante a eleição para diretores, e em alguns outros momentos, os educadores e funcionários das escolas de Duque de Caxias esqueceram-se do compromisso com a qualidade do ensino, permitindo que a escola continuasse perpetuando a ideia de escola que permeava a sociedade no início do século passado e que seus alunos, sendo eles da classe popular, não tivessem conhecimento de como exercer sua cidadania através do voto, haja vista terem, aparentemente, em sua maioria, seguido a lógica do interesse próprio e influenciado seus alunos a agirem da mesma forma. Ficou a impressão de que uma série de valores positivos foram deixados em segundo plano.

Sobre a qualidade do ensino oferecido nas escolas, vale ressaltar a necessidade de considerar a posição central ocupada por alunos e professores. Como também vale analisar a importância dessas relações, tanto em seu aspecto pedagógico, quanto em seu aspecto afetivo. É necessário que exista uma boa relação entre alunos e professores para que a aprendizagem se efetive, conforme Freire (1996) destaca

... se, como professor, não me acho tomado por este outro saber, o de que preciso estar aberto ao gosto de querer bem, às vezes, à coragem de querer bem aos educandos e à própria prática educativa de que participo. Esta abertura ao querer bem não significa, na verdade, que, porque professor me obrigo a querer bem a todos os alunos de maneira igual. Significa, de fato, que a afetividade não me assusta, que não tenho medo de expressá-la. Significa esta abertura ao querer bem a maneira que tenho de autenticamente selar o meu 


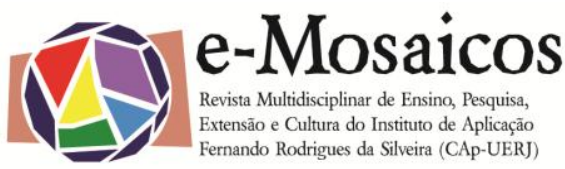

DOI: $10.12957 /$ e-mosaicos.2017.30483

compromisso com os educandos, numa prática específica do ser humano (FREIRE, 1996, p. 52).

Durante o processo eleitoral, em que objetivos estavam centradas as atividades desenvolvidas? Não seria este mais um momento de colocar os alunos como protagonistas em seus processos de construção do conhecimento? Parece que em muitas unidades escolares da rede o foco da qualidade da educação desviou-se, tendo, muitos dos envolvidos dado mais atenção a interesses próprios.

Em relação à opinião quanto ao processo de eleição, a maioria das pessoas entrevistadas posicionou-se a favor da realização da eleição, valorizando-a como um processo democrático, mas também se identificou o desgaste emocional gerado durante o evento, além de várias e significativas outras dificuldades, entre as quais as agrupadas a seguir:

\section{1 - A pouca maturidade dos envolvidos}

Ao falar da eleição para diretores uma professora regente diz: "Penso ser a situação ideal para a gestão da escola pública, mas especificamente em Caxias considero alguns critérios confusos e a não obrigatoriedade da formação em gestão escolar, a meu ver, foi um erro."

Para uma Orientadora Pedagógica da rede o processo foi favorável, apesar de algumas falhas devido a ser pioneiro no município:

O processo, como foi pioneiro no município, foi a primeira vez que ele se realizou, tudo o que aconteceu... as falhas... qualquer descaminho que possa ter acontecido no processo fazia parte porque era tudo muito novo para a rede, então foi uma experiência gratificante, acho que a rede aprendeu muito com esse processo e marcou o território porque agora outra gestão que vá assumir a Secretaria de Educação, o governo municipal vai ter que enfrentar o processo de eleições porque antigamente eram indicações e era um sonho de toda a categoria que os diretores fossem eleitos. Então dessa vez eu acho que vai ser difícil voltarmos a ter direção indicada porque já provamos que é possível fazer eleição.

Já uma Orientadora Educacional disse que:

No que se refere ao processo considero que tudo foi muito repentino e automático. Surgiu o decreto, estabeleceu o calendário, e cumpriuse o ritual, denominado democrático. Acho que ainda que fosse um a realização de um sonho coletivo: eleição de gestores, a comunidade 
e-Mosaicos - Revista Multidisciplinar de Ensino, Pesquisa, Extensão e Cultura do Instituto de Aplicação Fernando Rodrigues da Silveira (CAp-UERJ) V. 6 - N. 13 - DEZEMBRO 2017 - ISSN: 2316-9303

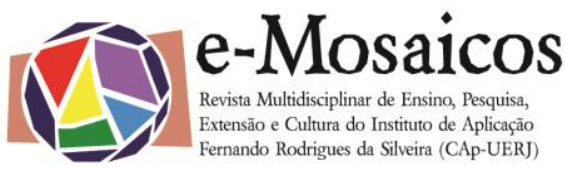

DOI: $10.12957 /$ e-mosaicos.2017.30483

escolar não estava madura para um processo atropelado. A deliberação do decreto, o processamento do pleito eleitoral pela SME e a conduta de alguns de nossos pares de trabalho assemelhou-se muito com as eleições para escolha do legislativo e do executivo tradicional. Pouco houve de processo democrático e pedagógico, para este fim.

Uma professora regente disse:

... o processo tinha tudo para dar certo, tinha tudo para ser uma inovação na rede pública de ensino, mas o que nós vimos e vivenciamos foi realmente muito decepcionante, um avanço da categoria para que a gente tivesse uma eleição para Diretores justa, foi simplesmente uma eleição fajuta, por que não teve mesmo tempo hábil de montar chapas, liberdade de expressão dentro da escola, oportunidade para as pessoas se apresentarem, para ter uma disputa limpa, uma disputa clara. Foi uma coisa muito feia, foi uma coisa que eu espero não ter que fazer parte desse contexto novamente, vou me abster desses momentos... infelizmente temos muito o que avançar, infelizmente não foi uma forma clara e justa de eleição, ...muita manipulação por trás dos acontecimentos, muitos gestos que a gente vê apenas distante para cargos maiores (Prefeitura, Estado, Presidência) e que aconteceu nessa disputa para esse cargo. E eu não gostei de nada do que vivenciei e na minha opinião foi uma coisa muito negativa, vivencio até os dias de hoje tenho que conviver com tudo aquilo que eu não concordo, mas como acredito em democracia a gente vai tentando levar como pode, mas se pudesse existir algum espaço para se colocar para poder reverter esse quadro, para ser uma coisa mais justa seria muito melhor para todos!

Um Agente Administrativo, contratado, disse:

Achei muito importante. Acredito que foi um primeiro passo na caminhada rumo a autonomia das unidades escolares e que vem a consolidar uma das bandeiras de luta do sindicato. Antes, pelo que sei, os Diretores eram indicados por políticos que sequer conheciam a realidade das escolas, agora, com esse processo, aqueles políticos perdem a vez e ganham espaço para a disputa os sujeitos que realmente conhecem e fazem o cotidiano escolar. O processo acaba por congregar num mesmo objetivo os profissionais da educação e a comunidade em que a escola está situada, uma vez que esta é convidada a participar de forma direta de todo o processo. Nesse sentido, o Diretor sendo eleito ganha legitimidade e legalidade para exercer sua gestão sem ter que se preocupar antes com as 
"conformidades" político partidárias. Contudo, cabe ressaltar que isso é algo totalmente novo nas escolas públicas municipais de Duque de Caxias e, portanto, ressaltar que só saberemos o resultado deste processo a médio prazo. No mundo da Educação nada é estanque como muitos governantes gostam de conceber.

Outra professora regente disse: "Foi muito bom haver esta mudança, mas penso que o processo pode ser aprimorado pelas escolas e funcionários."

Ainda outra professora disse: "Bem, acredito que este processo está longe de ser uma prática democrática e participativa. Faltou debate, faltaram propostas, faltou entendimento do processo eleitoral por parte da comunidade."

Presente nas falas acima o otimismo parece bem tímido, frente as inseguranças e desafios citados. É possível perceber que, embora a maioria se coloque a favor da existência do processo eleitoral, acredita-se que as coisas poderiam ter acontecido com mais planejamento, de forma a dar maior conhecimento e maturidade para as pessoas. Uma das falas acima evidencia o quanto os acontecimentos foram estanques, embora se pudesse planejá-los com antecedência e com a participação das comunidades escolares. Também se observa terem sido deixados de lado, de acordo com as falas, princípios como a ética e o respeito.

\section{2 - Falta de informação e pouca divulgação}

Uma professora regente, no momento licenciada, que esteve na escola durante o período da eleição, disse: "Penso que a eleição foi pouco divulgada. Poderia ter havido mais de uma chapa. Na minha escola ficou parecendo um refendo para a atual direção."

A fala dessa professora revela uma espécie consequência do pouco planejamento. Será que as pessoas estavam cientes de todo andamento do processo eleitoral desde a publicação? Ainda se faz necessário pensar em como a comunidade escolar está vendo esse evento na escola. Se há pouca divulgação, pode ser que se compreenda que o processo eleitoral nas escolas tenha pouco ou nenhum valor.

\section{3 - Sobre o evento em si}

Uma Diretora eleita durante esse primeiro processo eleitoral disse: "Acho justo que as pessoas possam escolher a Direção da escola, já que vivemos em uma democracia."

Já um Orientador Pedagógico de outra Unidade Escolar disse: 
Sinteticamente: eleições periódicas, com mandatos definidos, são positivas. Creio que os processos que acompanhei mais de perto transcorreram dentro de razoável normalidade, embora as comissões eleitorais de alguns lugares tenham pecado pela "omissão no uso da máquina pública" por gestões que concorriam.... Idealmente, creio que um sistema que envolvesse a imersão de candidatos no universo concreto de gestão que os espera e uma seleção prévia pré-eleitoral seria o melhor.

Para outro Agente Administrativo, funcionário contratado, a eleição foi um processo favorável:

Só que foi muito tarde, pois deveria ser no início do mandato do prefeito, ou melhor há uns três anos atrás, pois haveria fiscalização adequada com o próprio criador das eleições de 2015. Pois atualmente está uma bagunça em alguns colégios e o problema será repassado ao novo prefeito em 2016 e que fará mais bagunça, mais do que já está! $E$ sobre a eleição nos dias de votação não teve fiscalização, da prefeitura, SME, SEPE, ... Então poderia ter fraude, sim!

Um professor de Língua Portuguesa se posicionou:

Acredito que se processou de maneira satisfatória. O ponto negativo é que a remuneração (gratificação) oferecida não é nada atrativa ocasionando grande indiferença dos profissionais em se candidatar. Isso gerou um grande número de direções que continuam a ser indicadas por falta de candidato local. Em outras unidades ocorreu chapa única composta pela direção anterior que acabou sendo legitimada no cargo.

Sob as variadas perspectivas, à primeira impressão, é possível perceber algumas problemáticas envolvidas no processo eleitoral que precisam ser repensadas, como a da discussão acerca do valor do processo eleitoral para a comunidade escolar e de como essa pode refletir na qualidade do ensino oferecido, a necessidade prioritária da ética e do respeito nos relacionamentos, bem como a questão da gratificação e da formação do candidato à Direção. Ainda merece atenção a questão da continuidade de gestão anteriormente indicada, posto que, em algumas realidades, talvez a comunidade escolar decidisse pela manutenção da direção já vigente. 
Coloca-se aqui a necessidade de mostrar para a comunidade escolar todas as alternativas para a escolha de uma equipe de gestores, implicando a ausência dessa abertura de possibilidades no engessamento do processo. A eleição é um processo de escolha democrático, não deve estar condicionada ao estabelecimento de critérios de participação alheios. Esses critérios devem ser pensados junto com a comunidade escolar.

Quando se fala, na escola, em democracia, em eleição, em participação e emancipação, está-se falando do ato de educar. Um ato político, como bem diz Paulo Freire, Patrono da Educação Brasileira.

\section{A RELAÇÃO INTERPESSOAL NO AMBIENTE ESCOLAR DURANTE O PROCESSO ELEITORAL}

Sobre os relacionamentos durante o processo de escolha dos Diretores, coloca-se a seguinte questão: "Como você vê a questão do relacionamento professor-aluno, escola-comunidade, durante o processo de eleição para Diretores?", para a qual se obtém as seguintes respostas, organizadas nas mesmas três categorias:

\section{1 - A pouca maturidade dos envolvidos}

Um Agente Administrativo, contratado, disse:

A relação professor-aluno, do meu ponto de vista, permaneceu indiferente, mantendo-se as distâncias e as aproximações de outrora. Agora, na relação com a comunidade, a relação apresentou-se de forma mais horizontal e com permanente diálogo entre os candidatos e seus possíveis eleitores. Vale lembrar que quando falo da escola estou falando do candidato à Direção e não do corpo de professores de modo geral, pois estes nem sempre estavam a favor dos candidatos de sua unidade. O diálogo foi mais entre candidatos e comunidade do que da escola com esta. Acredito que foi mais por uma questão de interesse, coisa que para o grupo de professores talvez não parecesse tão significativa. Vendo o lado da comunidade, foi para eles o momento de estar participando das decisões da escola de seus filhos. Se sabiam a que estavam participando não posso afirmar, mas era notório seu envolvimento no processo. Acredito que aproximou, de certa forma, a comunidade à escola. Nesse sentido, a medida que o candidato teve que conquistar votos, obrigatoriamente teve que dialogar com esses sujeitos, logo pode sentir, assim esperase, os anseios e necessidades da realidade da qual irá participar pelos próximos dois anos. 
Ainda uma professora regente já citada e que também trabalha em outra rede municipal de ensino, comentou: "Sabendo a realidade de duas redes de ensino acho muito benéfica a eleição. $O$ problema são os critérios mal elaborados que interferem nas relações e tornam o candidato quase subserviente aos alunos e demais votantes"

A professora licenciada disse: "Esse processo de relacionamento não variou muito, mas permitiu ouvir mais de perto a comunidade."

Já o Orientador Pedagógico citado:

Regra geral, as professoras se portaram exemplarmente junto às crianças durante a eleição. Quando o assunto nascia, elas procuravam destacar a importância do processo e o que avaliar nos candidatos do que fazer panegíricos para $\mathrm{A}$ ou $\mathrm{B}$. Todavia, destaco que nossos alunos não votam (noves fora o EJA, onde, com uma exceção, a postura acima se manteve) e que eu não sei se com a forte pressão que as professoras contratadas sofreram elas aguentariam a barra. Na relação escola comunidade, a situação já foi diferente, talvez uma iniciativa desesperada de contra-atacar a forte penetração que uma candidatura tinha no bairro, a Direção anterior apelou para a difamação e a divulgação de supostas medidas negativas que sua adversária tomaria. Essa foi a pior parte do processo e que foi vencida mais pelo descrédito que a gestão anterior gozava do que por conta de medidas especificas da candidatura difamada.

Uma professora regente de outra Unidade Escolar ainda não citada comentou:

Nunca pensei ver tanta maldade quanto vi na minha escola ano passado. Foi o caos, brigas, processos, calunia, difamação. Amizades de anos desfeitas por um cargo. A minha escola é ... A Direção ganhou, a briga continuou e ela foi afastada temporariamente por estar sendo investigada. O Vice assumiu, não aguentou, e os dois pediram exoneração. A escola está há um tempão sem Direção, só com supervisoras. Dizem que ninguém quer assumir a escola.

A professora que faz menção a ter um espaço para se colocar a respeito do processo eleitoral relatou:

Foi extremamente proibido fazer comentários em sala de aula a respeito das chapas, das candidaturas dessas pessoas que se propuseram a participar das eleições e então muitos professores 
DOI: $10.12957 /$ e-mosaicos.2017.30483

ficaram sem comentar e se comentassem era motivo de denúncia, por que achavam que estavam induzindo os alunos a fazerem as suas escolhas e não podia, quando pode fazer foi uma coisa constrangedora por que se usou de má fé e de recursos muito estúpidos, tipo, eu vou entrar na escola para fazer campanha por que estou fora do horário de trabalho, foi uma coisa muito complicada. Ferindo todas as expectativas de uma eleição transparente, foi uma eleição induzida por um grupo que se fez presente da pior forma possível no contexto de uma eleição democrática para a Direção dentro da escola. Isso que estou dizendo foi algo que eu vivenciei no processo de eleição exclusivamente na minha escola, não sei no âmbito da Prefeitura de Caxias como se deu isso, mas essa única Unidade Escolar que eu participei e onde estou até os dias de hoje, foi dessa maneira, as chapas não foram conduzidas da mesma forma...

Para a Orientadora Educacional:

...um espaço tenso e velado inicialmente, devido às normativas presentes: predominantemente orientadas pelo não pode isto, não pode aquilo. Depois, em algumas Unidades Escolares, houve tensão devido à postura de alguns atores sociais.

Uma outra professora, ex-diretora, colocou sua opinião:

Acho que estamos engatinhando... as pessoas ainda não têm maturidade. Votam nos que oferecem mais flexibilidade, não por competência. A coisa não é diferente quando vamos às urnas eleger nossos representantes. Optamos pelos que nos oferecem algo... e assim aconteceu em várias escolas.

Se, em relação às falas sobre a eleição, a pouca maturidade teve peso forte, quando se fala das relações durante o período de tempo que compreendeu esse processo, a situação fica ainda mais complicada. Nas falas ficaram expostas atitudes dos sujeitos envolvidos e mostraram o quanto a comunidade escolar, incluindo professores, alunos e responsáveis, se afastaram da ideia de um evento que tivesse objetivo de aprendizagem, que fosse pedagógico, já que todo caminhar de uma unidade escolar deve acontecer nesse sentido. De forma que se pode entender que o não planejamento junto com a comunidade escolar evidenciou qual valor estava sendo dado àquele evento. As pessoas não tiveram tempo de compreender do que o evento "Primeira Eleição Para Diretores" tratava. 


\section{2 - Falta de informação e pouca divulgação}

Uma das professoras já mencionadas disse: "Com sinceridade, não creio que os pais tiveram muita consciência da importância da eleição e de sua participação no processo..."

E ainda outra: "...eu gosto muito da minha escola, das pessoas, porém não houve divulgação da eleição. As crianças não sabiam o que era eleição, não foi comunicado a elas, não houve consciência sobre o ato de votar."

E a professora que deseja espaço para falar disse:

... A escola fechou as portas para a comunidade em relação à divulgação desse processo de eleição, a comunidade estava totalmente desinformada, não sabiam absolutamente nada a respeito desse processo .... vivenciamos momentos difíceis, constrangedores ... e os alunos, para eles era indiferente porque não houve nenhum tipo de trabalho direcionado a eles, então quem desse vantagens ou oferecesse regalias para eles estava de bom tamanho e para a comunidade a mesma coisa, tendo aula e os recursos... estava de bom tamanho também, não tinham visão política, não tinham uma visão de Unidade Escolar mesmo.

Infelizmente, embora não se tenha revelado o interesse por trás dessas ações, houve quem negasse divulgar informações durante o processo eleitoral, tornando as coisas difíceis para a comunidade escolar que, sem perceber, acaba sendo manipulada pelo desconhecimento. Aqui, fica clara a postura reprodutora dos sujeitos.

\section{3 - Sobre o evento em si}

A já mencionada Diretora eleita contrapôs:

Acho que na nossa Unidade foi bem tranquilo, o professor queria a mudança, já não estavam gostando de como estava mais e, apesar dos alunos lá da escola não votarem, participaram bastante. Os alunos de quarto e quinto ano, que já tinham noção maior questionaram: "Mas a gente queria votar, tia! A gente já sabe o que a gente quer." E precisei explicar que só do sexto ano em diante e que aqui só pai pode votar, e eles ficaram muito chateados de não poderem participar. E o mais bacana no processo, que aí a gente já envolve a escola e a comunidade, é que a participação dos pais na nossa Unidade foi bem grande, tivemos pais vindo votar no sábado, e 
DOI: $10.12957 /$ e-mosaicos.2017.30483

teve escola que tinha que ligar para os pais irem votar, e na nossa escola tivemos doze ou treze pais que vieram votar por conta própria no sábado... o tempo estava ruim... já tínhamos atingido a meta na sexta-feira, mas no sábado a gente teve pais e a comunidade ficou bem envolvida, bem participativa, foi bem legal a eleição. Também tivemos profissionais que vieram durante a semana e que veio sábado votar. Fiquei bem satisfeita e me senti bem por causa dessa participação da comunidade, é uma comunidade que se for chamada participa e muitos vieram por causa dos filhos, principalmente de quarto e quinto ano com a fala de que "se eu não viesse meu/minha filho(a) me matava" e as crianças me encontravam no corredor e diziam: "tia, minha mãe já veio votar, hein!" Foi um processo muito legal... o processo, tem que existir esse processo de eleição nas escolas! Que em Caxias não tenha um retrocesso em relação a isso, não por que fui eleita, mas porque acho que o processo tem que ser esse mesmo de eleição, tem que ser dessa forma!

Para a Orientadora Pedagógica já citada:

O processo de eleição foi uma rica oportunidade para que os professores reconhecessem o papel da comunidade escolar. Como o voto dos alunos e responsáveis tinha o mesmo peso que o voto dos professores, fez-se necessário estreitar os laços, reconhecendo que a escola não é feita só de professores e que o poder decisório está nas mãos de todos. Também asseguro que o fato de as eleições para o Conselho Escolar terem acontecido simultaneamente às eleições para diretores foi um grande marco. Dessa forma, Diretores eleitos não cooptariam um Conselho Escolar de pessoas "amigas", foi aberta uma chance para que responsáveis que nunca antes tiveram espaço na escola, tivessem vez e voz no Conselho.

Uma professora encerra: "Professor-aluno, tranquilo. Mas estive na comissão eleitoral. Procurei ser bem imparcial. Escola-comunidade foi difícil porque uma das chapas fez ofertas difíceis de cumprir. No entanto, a comunidade estava atenta pois esta chapa não ganhou..."

Feitas as colocações, algumas questões a serem repensadas e reorganizadas sobre os relacionamentos durante o período eleitoral foram demarcadas: A da falta de maturidade dos envolvidos no processo; a da desinformação e ausência de divulgação dos acontecimentos durante a eleição e da própria eleição, para a comunidade escolar (incluindo alunos e responsáveis), bem como para a comunidade ao redor da escola; a da ausência de discussão acerca de como o processo deveria acontecer e consequente ausência dessa mesma discussão com os alunos e responsáveis, professores e funcionários dentro das escolas; a notada reprodução 


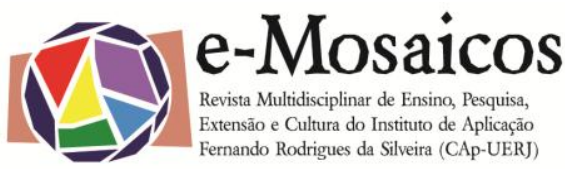

DOI: $10.12957 /$ e-mosaicos.2017.30483

das atitudes tomadas por cidadãos durante processos eleitorais em outras esferas maiores e os conflitos entre chapas candidatas e seus aliados, incluindo constrangimento, ofensas, denúncias, etc.

Tornou-se evidente também que a eleição apresentou muitos pontos positivos, destacando-se a necessidade de uma aproximação da escola com a comunidade, a participação efetiva dos responsáveis em algumas unidades escolares e a desvinculação da Direção da escola pública da política partidária nas escolas onde a Direção foi eleita e não somente perpetuada por falta de opção aos eleitores.

Porém, é sobre os aspectos acima enumerados que se faz necessária uma retomada, não somente aqui, mas principalmente no coletivo de professores, funcionários, alunos e responsáveis da rede municipal. O que se pode fazer, por exemplo, para amadurecer o entendimento dos envolvidos para um próximo processo eleitoral? Organizar cursos, palestras nas escolas, seminários aos professores e funcionários? Com relação à divulgação, será que seria viável uma campanha mais expressiva por parte da Secretaria de Educação e com maior antecedência? Como promover o debate saudável acerca deste processo? Todos os envolvidos podem participar na construção de requisitos para organizar a próxima eleição? Será necessário organizar uma representatividade para este fim? $\mathrm{E}$, por último, a questão da geração dos conflitos durante este processo, como pode ser tratada? Existe algum meio de amenizar esse problema?

Perrenoud (2000) afirma que

Para as normas e os valores, assim como para os saberes, o sistema educativo coloca os alunos em distância desigual da norma escolar, simplesmente por causa dos programas. Porém, ainda aqui a maneira como o professor retoma, interpreta e operacionaliza o currículo formal, pode acentuar ou atenuar essa distância (PERRENOUD, 2000, p. 81).

Conforme comentado por uma Orientadora Pedagógica, pode se conceber como compreensível que um fato pioneiro num sistema de ensino venha acompanhado de inseguranças, incertezas e erros, porém, e por esse mesmo motivo, se faz necessária uma busca por informações e ações que possam contribuir para o refinamento deste processo para que o mesmo não venha a ser vencido por outros processos de escolha anteriormente legitimados. A luta pela legitimação do processo de escolha democrática passa por reflexões com seus sujeitos, num paradigma em que a rede municipal possa "atenuar" a "distância" existente entre esses mesmos sujeitos. Passa por uma análise de como alunos e professores viram o processo eleitoral.

Ainda na forma como o processo é tratado dentro do ambiente escolar, é possível que residam as causas dos conflitos gerados neste período. A violência como 
DOI: $10.12957 /$ e-mosaicos.2017.30483

reflexo de processos de exclusão talvez não seja uma novidade, mas pode esse assunto ser novamente tratado para o avanço relativo a eleições futuras?

\section{CONSIDERAÇÕES FINAIS}

Participar de um momento inédito na história de um município onde as relações são marcadas pelas ações e intenções da política partidária, principalmente dentro das Unidades Escolares como foi a Primeira Eleição para Diretores das Unidades Escolares de Duque de Caxias, faz crer que é possível fazer democracia dentro da escola pública municipal.

Uma questão fica muito clara: É necessário garantir a continuidade da escolha democrática dos Diretores Escolares em Duque de Caxias! Para isso, no entanto, existe a premente necessidade da legitimação desta escolha, subsidiando os avanços progressivos em cada Unidade Escolar. Documentando fatos positivos, com 0 crescente aumento da participação da comunidade escolar na tomada de decisões nos ambientes escolares, tanto através do voto para escolher seus dirigentes, quanto na participação nos Conselhos Escolares e nas escolhas dos membros que o irão compor.

As rivalidades ocorridas no período de eleição precisam ser atenuadas, amenizadas, para que o aluno da rede municipal saiba que numa democracia de verdade, a vontade e a opinião do outro devem ser respeitadas, mesmo que não haja concordância com as suas próprias. A necessidade de praticar a tolerância aparece de modo muito claro.

Para alunos, professores, responsáveis e funcionários, a escola ideal pode assumir diferentes características e a busca do consenso entre estas partes vem se tornando um desafio que a escola precisa mediar. Na maioria das escolas, foi possível observar que as pessoas se sentiram satisfeitas com os resultados da eleição, mas como foi que o desenrolar deste momento contribuiu para a formação dos estudantes? Para eles ficou clara a ideia de democracia como prática de respeito as decisões tomadas pelo coletivo ou apenas presenciaram uma reprodução do que vemos na sociedade atual? Como manter o foco do respeito à diferença dentro do ambiente escolar durante este período? Princípios como a ética e o respeito devem ser ensinados e praticados antes mesmo de se pensar uma escola gerida por um Diretor Eleito.

\section{REFERÊNCIAS BIBLIOGRÁFICAS}

BRASIL. Constituição da República Federativa do Brasil(1988). Disponível em http://www.planalto.gov.br/ccivil_03/constituicao/constituicao.htm . Acesso em: 15 de setembro de 2017. 
DOI: $10.12957 /$ e-mosaicos.2017.30483

- Lei de Diretrizes e Bases da Educação Nacional - Lei no 9.394 de

20/12/1996. Disponível em http://www.planalto.gov.br/ccivil_03/Leis/L9394.htm . Acesso em: 18 de setembro de 2017.

. Ministério do Planejamento, Orçamento e Gestão. Instituto Brasileiro de Geografia e Estatística (IBGE). Índice de desenvo/vimento humano dos municípios do Estado do Rio de Janeiro. Disponível em https://cidades.ibge.gov.br/v4/brasil/rj/duquede-caxias/pesquisa/37/0?localidade $1=330330$

BRAZ, Antônio Augusto; ALMEIDA, Tânia Amaro. De Meriti a Duque de Caxias: Encontro com a História da Cidade. Duque de Caxias (RJ), APPH-Clio, 2010.

FREIRE, Paulo. Pedagogia da autonomia: saberes necessários à prática educativa. São Paulo: Paz e Terra, 1996.

PERRENOUD, Philippe. Pedagogia diferenciada: das intenções à ação/Tradução Patrícia Chittoni Ramos. Porto Alegre: Artmed, 2000.

PREFEITURA MUNICIPAL DE DUQUE DE CAXIAS. Câmara Municipal de Duque de Caxias. Lei No 2.713, de 30/06/2015. Disponível em http://www.cmdc.rj.gov.br/?p=5837. Acesso em: 18 de abril de 2016.

. Secretaria Municipal de Educação. Decreto 6.542, de 11/05/2015 publicado no Boletim Oficial nº 6228 de 12/05/2015. Dispõe sobre Eleições para Diretores e Vice-Diretores das Unidades Escolares do município de Duque de Caxias.

. Secretaria Municipal de Educação. Portaria no 34, de 21/05/2015. Sobre o calendário do processo eleitoral.

. Secretaria Municipal de Educação. Portaria no 61, de 17/08/2015. Da instalação das comissões organizadoras do processo eleitoral.

. Secretaria Municipal de Educação. Portaria no 80, de 23/09/2015. Prorroga o prazo de inscrição para algumas Unidades Escolares.

. Secretaria Municipal de Educação. Portaria no 64, de 02/09/2015. Alteração do calendário do processo eleitoral.

. Secretaria Municipal de Educação. Orientações Gerais: $1^{a}$ Eleição para Diretores, Vice-Diretores e Conselhos Escolares.

Secretaria Municipal de Educação. Regimento da Primeira Eleição Para Diretores e Vice-Diretores das Unidades Escolares da Rede Pública Municipal de Duque de Caxias. Publicado em 24/082015. 
SILVA, André Tenreiro Jesus da. Atlas escolar do município de Duque de Caxias. Duque de Caxias/RJ. SME/DC, 2012. Disponível em http://smeduquedecaxias.rj.gov.br/nead/Biblioteca/Produ\%C3\%A7\%C3\%B5es\%20S ME/Atlas/atlas.pdf . Acesso em 15 de setembro de 2017.

Recebido em 20 de setembro de 2017.

Aceito em 13 de outubro de 2017. 